\title{
CEREBRAL LANGUAGE DOMINANCE: A GROSS STUDY
}

\author{
Usha Devi Keezhathil Bhargavi ${ }^{1}$, Lathi Kumari Kalyani Kutty Amma²
}

${ }^{1}$ Additional Professor, Department of Anatomy, Medical College, Trivandrum.

${ }^{2}$ Additional Professor, Department of Anatomy, Medical College, Alappuzha.

\begin{tabular}{l}
\hline ABSTRACT \\
BACKGROUND \\
Apparent interhemispheric differences in language may be associated with anatomical asymmetries. Cerebral asymmetry and \\
dominance are well-established entities. \\
OBJECTIVES- \\
Gross anatomical comparative study of the lateral sulcus, planum temporale and Heschl's gyrus of the right and left cerebral \\
hemispheres in different age groups.
\end{tabular}
DESIGN-

A post-mortem study of specimens from different age groups - cross-sectional study. SETTINGS-

Department of Anatomy, Medical College, Thiruvananthapuram; Mortuary, Medical College Hospital, Thiruvananthapuram; 50 post-mortem brain specimens from different age groups were studied.

\section{MATERIALS AND METHODS}

Specimens were grouped according to the age, sex and handedness. Handedness was ascertained from the immediate relatives. The length of the post central horizontal segment of lateral sulcus, the angulation of the posterior ramus of the lateral sul cus, the size of planum temporale and the Heschl's gyrus were compared between the hemispheres. The data was analysed statistically and the levels of significance studied.

Inclusion Criteria-

Post-mortem specimens of all age groups where both sides of the brain were intact.

Exclusion Criteria-

1. Brain where both sides were not intact. E.g. specimens from road traffic accidents.

2. Age groups where post-mortem specimens are few. E.g. above 80 years.

3. Specimens from cases of congenital anomalies.

4. Cases where the handedness was not known.

\section{RESULTS}

1. The post central horizontal segment of the left lateral sulcus was longer than the corresponding segment on the right in $90 \%$ of specimens.

2. Early bending of the right lateral sulcus was noted in $90 \%$ of specimens.

3. The planum temporale was larger on the left in $90 \%$ of specimens.

4. $98 \%$ of specimens showed single Heschl's gyrus.

\section{CONCLUSION}

The following conclusions could be drawn from the above study.

1. Cerebral asymmetry of the human brain with regards to the language areas was confirmed.

2. As the study included only right handers, a left-handed dominance for language was observed.

\section{KEYWORDS}

Cerebral Asymmetry, Language Areas, Lateral Sulcus, Planum Temporale, Heschl's Gyrus.

HOW TO CITE THIS ARTICLE: Bhargavi UDK, Amma LKKK. Cerebral language dominance: A gross study. J. Evolution Med. Dent. Sci. 2016;5(75):5591-5596, DOI: 10.14260/jemds/2016/1262

Financial or Other, Competing Interest: None.

Submission 10-08-2016, Peer Review 02-09-2016,

Acceptance 09-09-2016, Published 19-09-2016.

Corresponding Author:

Dr. Usha Devi Keezhathil Bhargavi,

Department of Anatomy,

Medical College, Trivandrum.

E-mail: ushakbdevi1@gmail.com

DOI: $10.14260 /$ jemds $/ 2016 / 1262$

(c) (i) $\ominus$

\section{INTRODUCTION}

Human beings are bestowed with the unique ability to converse through language. This boon enables man to conquer the peaks of social life. Speech is but one modality for the expression of language. Speech; however, has a special importance because it is the primary, first learned modality for hearing language users. The exact mechanism behind normal language acquisition, storage and retrieval are not well understood. 
'There are innate and genetic factors, hormonal and environmental influences that determine normal acquisition of language.

The references to disorders of speech dates back to 400 B.C. Superstition, mysticism, doctrines, ideologies, etc. that prevailed over the centuries gave way to clear scientific understanding at the turn of the 18th century.

Broca's observation that we speak with the left hemisphere stimulated a good deal of clinical research into the anatomical basis of language.

It is now a well-established fact that human language functions depend more on one cerebral hemisphere than on the other.

Ever since Broca discovered the functional lateralisation of the human brain, structural asymmetries have been sought to explain left hemisphere specialisation for language.

Gross anatomical difference between the right and left side of the brain is suggested as the basis of cerebral dominance of language development. This study is to find out whether such gross anatomical changes exist.

\section{MATERIALS AND METHODS}

The work was done on post-mortem specimens from different age groups.

\section{Materials}

Human brain was chosen for the study of language areas. A total of 50 specimens were included in the present study. The specimens were those of persons of both sexes, belonging to various age groups.

\section{Inclusion Criteria}

All post mortem brain specimens of different age groups where both sides of the brain were intact.

\section{Exclusion Criteria}

1. Brains where both sides were not intact, e.g. specimens from traffic accidents.

2. Specimens from cases with congenital anomalies and infections.

3. Adult brains where the handedness was not known.

Specimens were grouped according to the age, sex and handedness. Handedness was ascertained from the immediate relatives. History of chronic ailments, speech and hearing disorder, previous medical and surgical history, etc. were enquired.

The brains were carefully stripped off the meninges and vessels so that sulci and gyri could be properly identified. The lateral sulcus was gently traced along its entire course. The upper and lower limits of the central sulcus was noted. The lower end of the central sulcus was taken as the anterior limit and the bifurcation or upward angulation of the lateral sulcus as the posterior limit. The distance between the two points was measured by means of scale and this distance was taken as the post-central horizontal segment. These segments were compared on both sides of the brain.

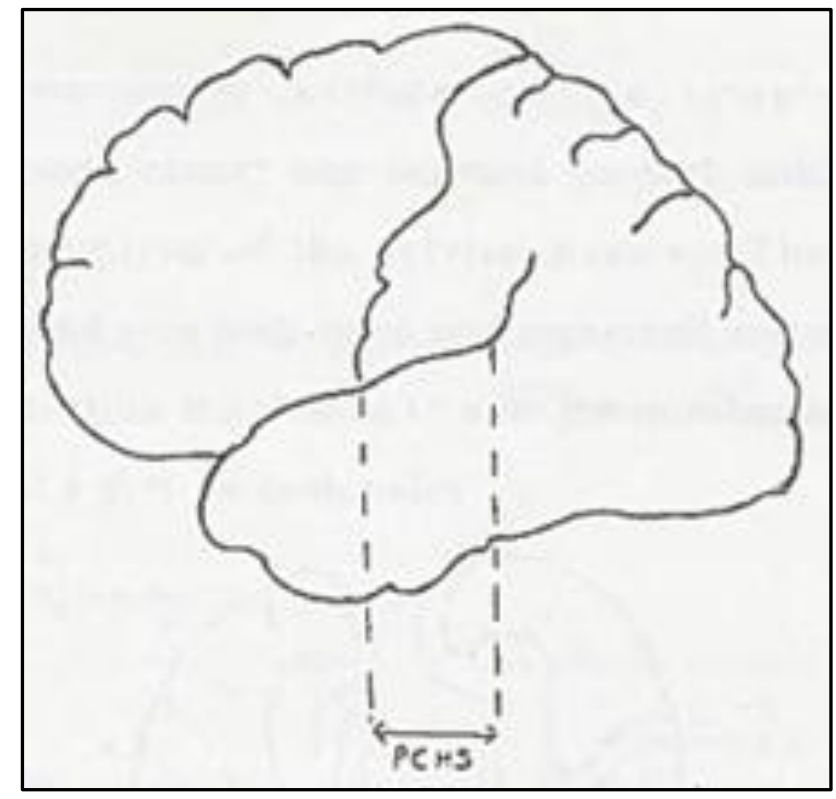

Fig. 1: Superolateral Surface of the Left Hemisphere showing the Two Ends of the Post-central Horizontal Segment (PCHS)

The point where the posterior ramus of the lateral sulcus started angulating upwards was noted on both hemispheres. This enabled to compare the early bending of the posterior ramus.

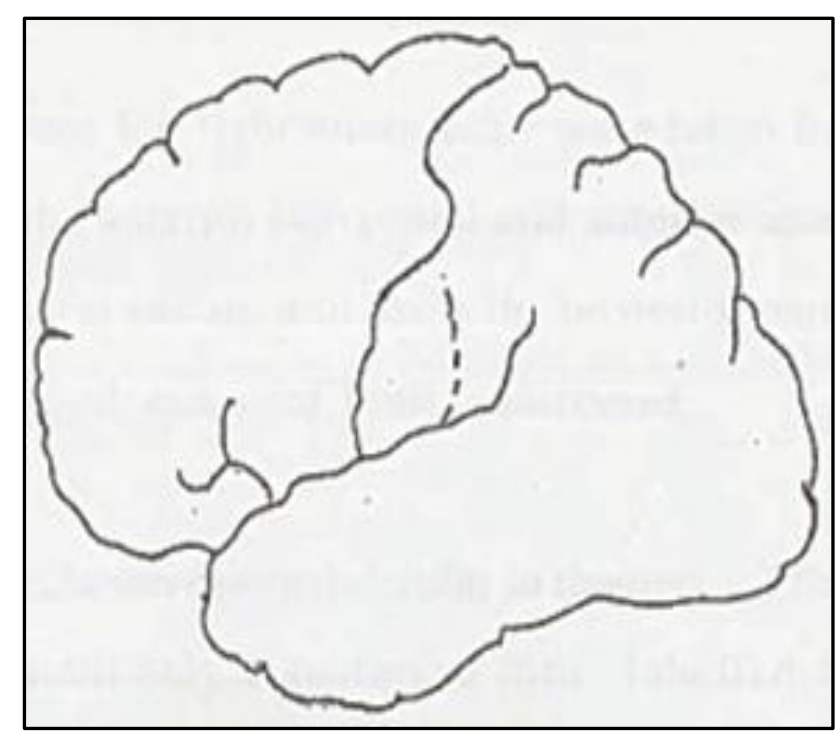

Fig. 2: Superolateral Surface of the Left Hemisphere showing the Upward Angulation of the Posterior Ramus of the Lateral Sulcus. Dotted lines denote early Bending of the Posterior Ramus on the Right

The upper surface of the temporal lobe (supratemporal plane) was exposed on each side by a cut made in the plane of the Sylvian fissure. The distance between $\mathrm{X}$ and $\mathrm{Y}$ on both sides was measured and compared. The same section enabled us to note the number and size of the Heschl's gyri on both sides. 


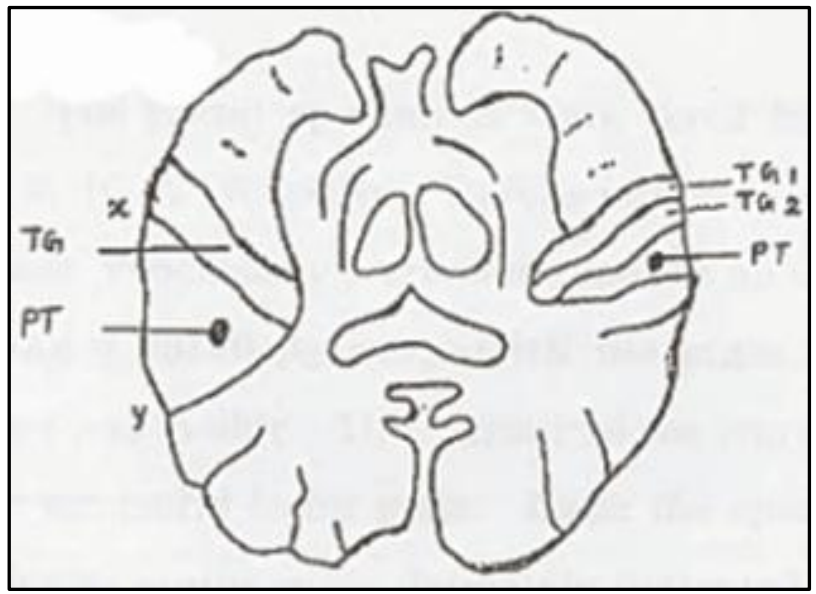

Fig. 3: Upper Surfaces of Human Temporal Lobes exposed by a cut on each side in the Plane of the Lateral Sulcus, showing points $x$ and $y$ PT - Planum Temporale TG Transverse Sulcus

\section{OBSERVATIONS}

The following features were studied.

Out of the fifty specimens, forty five showed a longer postcentral horizontal segment on the left hemisphere, whereas in five of them the post-central horizontal segment of the lateral sulcus was equal on both sides (Table 1). Early bending of the posterior ramus of the right lateral sulcus was noticed in $90 \%$ of the cases.

\section{Planum Temporale}

Of the fifty specimens in the age group 10-80 years, the planum was bigger on the left side in forty five specimens (Photo 1 and Table 1). In the specimens which showed equal post-central horizontal segments on both sides, the planum temporale too was equal. One specimen had a bigger right planum temporale.

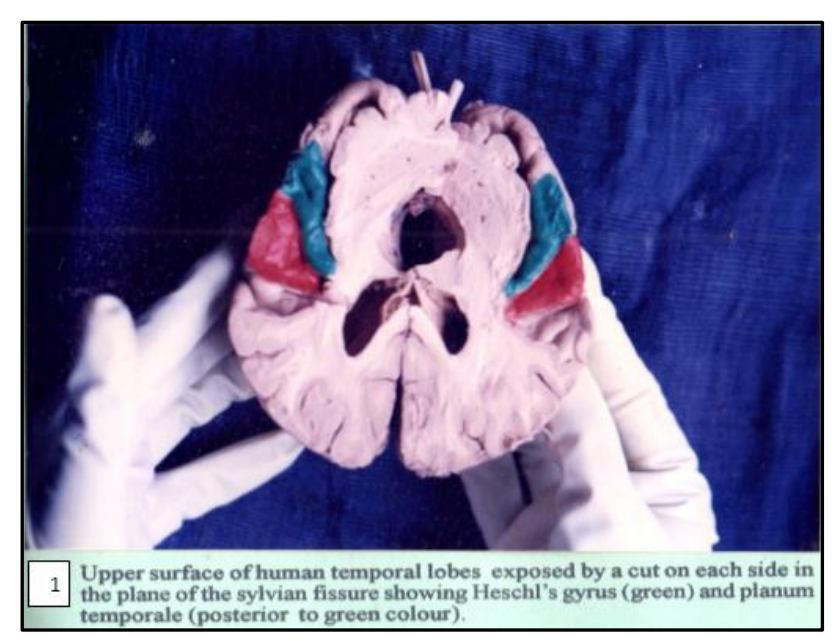

49 specimens showed single Heschl's gyrus (Photo 1 and Table 1). There was more than one Heschl's gyrus in only one specimen and that was on the left. The Heschl's gyrus was larger in the left in three specimens. The specimen that had a larger right planum temporale showed a single Heschl's gyrus on both sides, but the one on the right was bigger.

\section{RESULTS}

1. The post-central horizontal segment of the left lateral sulcus was longer than the corresponding segment on the right in $90 \%$ of specimens.

2. Early bending of the right lateral sulcus was noted in $90 \%$ of specimens.

3. The planum temporale was larger on the left in $90 \%$ of specimens.

4. $98 \%$ of specimens showed single Heschl's gyrus on the corresponding Hemispheres.

\section{DISCUSSION}

The Sensory speech area/General interpretative area/Gnostic area/Wernicke's area/Area 22 (Fig. 4) is situated in the superior temporal gyrus with extensions around the posterior ramus of the lateral sulcus.

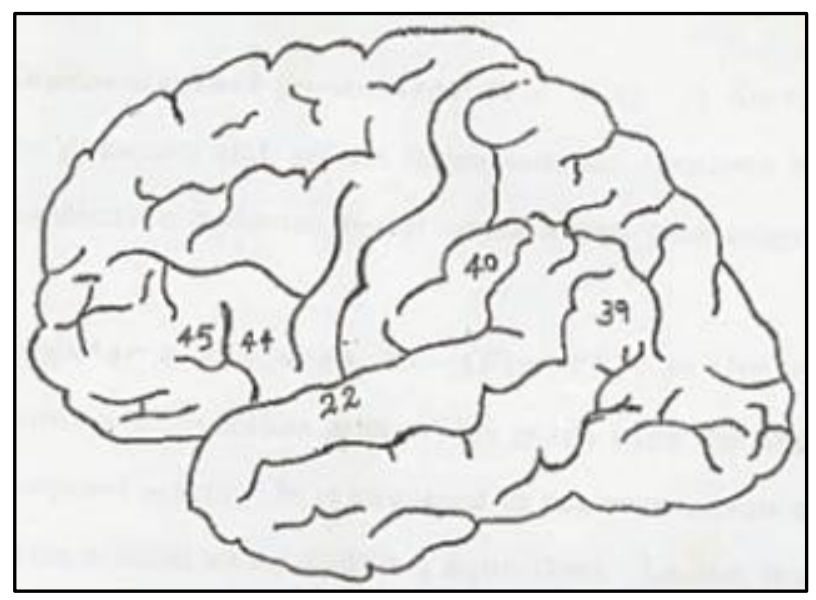

Fig. 4: The Superolateral Surface of the Left Hemisphere showing the Language Areas

\begin{tabular}{|c|c|c|c|c|c|c|c|c|c|}
\hline \multirow[b]{2}{*}{$\begin{array}{l}\dot{z} \\
\dot{\boldsymbol{n}}\end{array}$} & \multicolumn{2}{|c|}{ PCHS } & \multicolumn{2}{|c|}{ PL. TEMP } & \multicolumn{2}{|c|}{ HES.GY. } & \multirow[b]{2}{*}{$\underset{0}{\infty}$} & \multirow[b]{2}{*}{ 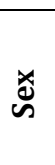 } & \multirow[b]{2}{*}{$\underset{\widetilde{I}}{\tilde{I}}$} \\
\hline & 屯্త & 苟 & 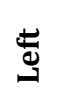 & 苛 & ఫ્ & 苛 & & & \\
\hline 1 & 3.0 & 2.5 & 2 & 1.8 & I & I & 42 & $F$ & $\mathrm{R}$ \\
\hline 2 & 5 & 4.5 & 4 & 3 & I & I & 36 & $M$ & $\mathrm{R}$ \\
\hline 3 & 4.5 & 3.5 & 3.5 & 2.5 & I & I & 15 & $\mathrm{~F}$ & $\mathrm{R}$ \\
\hline 4 & 3 & 3 & 2.5 & 2.5 & I & I & 35 & $\mathrm{~F}$ & $\mathrm{R}$ \\
\hline 5 & 3.8 & 3.5 & 3.2 & 3 & I & I & 45 & M & $\mathrm{R}$ \\
\hline 6 & 4.5 & 4.1 & 3.6 & 2.8 & II * & I & 35 & $\bar{M}$ & $\mathrm{R}$ \\
\hline 7 & 4 & 4 & 3 & 3 & I & I & 24 & M & $\mathrm{R}$ \\
\hline 8 & 4 & 3 & 3.5 & 2.7 & I & I & 40 & M & $\mathrm{R}$ \\
\hline 9 & 4.8 & 4 & 4 & 3 & I & I & 29 & $\bar{M}$ & $\mathrm{R}$ \\
\hline 10 & 4 & 4 & 3.5 & 3.5 & I & I & 20 & $\mathrm{M}$ & $\mathrm{R}$ \\
\hline 11 & 4 & 3.5 & 3.5 & 3 & I & I & 55 & $\mathrm{M}$ & $\mathrm{R}$ \\
\hline 12 & 4 & 3.1 & 3.5 & 3 & I & I & 45 & $\mathrm{M}$ & $\mathrm{R}$ \\
\hline 13 & 4.1 & 3.5 & 3.5 & 2.8 & I & I & 19 & M & $\mathrm{R}$ \\
\hline 14 & 4.2 & 2.9 & 1.8 & 1.3 & I & I & 58 & $\mathrm{M}$ & $\mathrm{R}$ \\
\hline 15 & 4 & 3 & 3 & 2.8 & I & I & 30 & F & $\mathrm{R}$ \\
\hline 16 & 4 & 3.2 & 3 & 2 & I & I & 18 & $\mathrm{M}$ & $\mathrm{R}$ \\
\hline 17 & 3.8 & 3 & 3 & 2.1 & I & I & 80 & $\mathrm{M}$ & $\mathrm{R}$ \\
\hline 18 & 4 & 3.5 & 3.5 & 2.8 & I & I & 55 & $\mathrm{M}$ & $\mathrm{R}$ \\
\hline 19 & 4 & 3 & 3.7 & 3.2 & I & I & 39 & $\mathrm{M}$ & $\mathrm{R}$ \\
\hline 20 & 4 & 3.2 & 3.5 & 3.1 & I & I & 22 & M & $\mathrm{R}$ \\
\hline
\end{tabular}




\begin{tabular}{|c|c|c|c|c|c|c|c|c|c|}
\hline 21 & 4.2 & 3.2 & 3.5 & 3 & $\mathrm{I}$ & $\mathrm{I}$ & 34 & $\mathrm{M}$ & $\mathrm{R}$ \\
\hline 22 & 3.7 & 3.5 & 3.2 & 3 & $\mathrm{I}$ & $\mathrm{I}$ & 23 & $\mathrm{M}$ & $\mathrm{R}$ \\
\hline 23 & 3.9 & 3 & 2.8 & 2 & $\mathrm{I}$ & $\mathrm{I}$ & 20 & $\mathrm{M}$ & $\mathrm{R}$ \\
\hline 24 & 4.5 & 4 & 4 & 3 & $\mathrm{I}$ & $\mathrm{I}$ & 44 & $\mathrm{~F}$ & $\mathrm{R}$ \\
\hline 25 & 3.8 & 3 & 2.9 & 2 & $\mathrm{I}$ & $\mathrm{I}$ & 26 & $\mathrm{~F}$ & $\mathrm{R}$ \\
\hline \multicolumn{10}{|c|}{ Table 1 } \\
\hline
\end{tabular}

PCHS- Length of post central horizontal segment of the lateral sulcus in $\mathrm{cm}$.

PL.TMP - Length of X-Y points on the planum temporale in $\mathrm{cm}$. HES.GY- Number and size

II*- Double Heschl's gyrus.

Han- Handedness.

\begin{tabular}{|c|c|c|c|c|c|c|c|c|c|}
\hline \multirow[b]{2}{*}{$\begin{array}{l}\dot{0} \\
\dot{z} \\
\dot{n}\end{array}$} & \multicolumn{2}{|c|}{ PCHS } & \multicolumn{2}{|c|}{ PL. TEMP } & \multicolumn{2}{|c|}{ HES.GY. } & \multirow[b]{2}{*}{$\stackrel{80}{80}$} & \multirow[b]{2}{*}{ 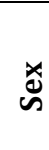 } & \multirow[b]{2}{*}{ శ్ } \\
\hline & Е્さ & $\underset{\vec{z}}{\overrightarrow{0}}$ & 坖 & $\begin{array}{l}\underbrace{}_{00} \\
00\end{array}$ & 屯্త & 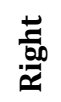 & & & \\
\hline 26 & 3 & 3 & 2.5 & 2.5 & I & I & 50 & $F$ & $\mathrm{R}$ \\
\hline 27 & 4.2 & 3.5 & 3 & 2.8 & $\begin{array}{c}\mathrm{I} \\
\mathrm{BIG}\end{array}$ & I & 47 & M & $\mathrm{R}$ \\
\hline 28 & 4.8 & 3.8 & 3 & 2 & $\begin{array}{c}\mathrm{I} \\
\mathrm{BIG}\end{array}$ & I & 12 & $\mathrm{M}$ & $\mathrm{R}$ \\
\hline 29 & 4 & 3 & 3.5 & 2.5 & $\mathrm{I}$ & $\mathrm{I}$ & 35 & $\mathrm{M}$ & $\mathrm{R}$ \\
\hline 30 & 3.5 & 3 & 2.3 & 2 & $\begin{array}{c}\text { I } \\
\text { BIG }\end{array}$ & I & 30 & $\mathrm{~F}$ & $\mathrm{R}$ \\
\hline 31 & 3 & 2.5 & 2.5 & 2 & I & I & 32 & $F$ & $\mathrm{R}$ \\
\hline 32 & 4.5 & 3.5 & 3.1 & 2 & I & I & 28 & $\mathrm{~F}$ & $\mathrm{R}$ \\
\hline 33 & 3.8 & 3 & 2.2 & 1.5 & I & I & 32 & $\mathrm{~F}$ & $\mathrm{R}$ \\
\hline 34 & 3.5 & 3 & 2.1 & 2 & I & I & 77 & $\mathrm{~F}$ & $\mathrm{R}$ \\
\hline 35 & 4.5 & 3.5 & 4 & 3 & I & I & 24 & $\mathrm{M}$ & $\mathrm{R}$ \\
\hline 36 & 3 & 3 & 2.5 & 2.2 & I & $\mathrm{I}$ & 62 & $\mathrm{M}$ & $\mathrm{R}$ \\
\hline 37 & 4.3 & 3.5 & 2.5 & 3 & I & $\begin{array}{c}\mathrm{I} \\
\mathrm{BIG}\end{array}$ & 29 & $\mathrm{M}$ & $\mathrm{R}$ \\
\hline 38 & 4 & 3 & 3.5 & 3 & $\mathrm{I}$ & I & 19 & $\mathrm{~F}$ & $\mathrm{R}$ \\
\hline 39 & 3 & 2.8 & 2.5 & 2 & I & I & 78 & $\mathrm{M}$ & $\mathrm{R}$ \\
\hline 40 & 4.8 & 4 & 4 & 3.1 & I & I & 26 & $\mathrm{~F}$ & $\mathrm{R}$ \\
\hline 41 & 3 & 2.5 & 2.5 & 2 & I & I & 70 & $\mathrm{M}$ & $\mathrm{R}$ \\
\hline 42 & 3.5 & 3 & 2.8 & 2 & $\mathrm{I}$ & I & 55 & $\mathrm{~F}$ & $\mathrm{R}$ \\
\hline 43 & 4.5 & 3.5 & 4.1 & 3 & I & I & 38 & $\mathrm{~F}$ & $\mathrm{R}$ \\
\hline 44 & 4 & 3 & 2.5 & 1.5 & I & I & 25 & $\mathrm{M}$ & $\mathrm{R}$ \\
\hline 45 & 3 & 2.8 & 2.5 & 2 & I & I & 71 & $\mathrm{M}$ & $\mathrm{R}$ \\
\hline 46 & 4 & 3 & 3 & 2.5 & I & I & 22 & $\mathrm{M}$ & $\mathrm{R}$ \\
\hline 47 & 3.8 & 2.9 & 3 & 2 & I & I & 52 & $\mathrm{M}$ & $\mathrm{R}$ \\
\hline 48 & 4 & 3.5 & 3 & 2 & I & I & 30 & $\mathrm{~F}$ & $\mathrm{R}$ \\
\hline 49 & 3 & 2.7 & 2.5 & 2 & I & I & 18 & $\mathrm{~F}$ & $\mathrm{R}$ \\
\hline 50 & 4 & 3 & 3 & 2 & I & I & 17 & $\mathrm{~F}$ & $\mathrm{R}$ \\
\hline
\end{tabular}

PCHS- Length of post central horizontal segment of the lateral sulcus in $\mathrm{cm}$. PL.TMP. Length of X-Y points on the planum temporale in cm. HES.GY- Number and size, Han- Handedness.

Heschl's gyrus:- (Photo 1) It is the transverse temporal gyrus (or gyri when present) bounded posteriorly by a complete transverse fissure and occupies the superior surface of superior temporal gyrus. The area posterior to the Heschl's gyrus (or gyri) is the planum temporale.

Angular gyrus/Area 39:- (Fig. 4) It is the visual auditory conversion area. This gyrus caps the superior temporal sulcus. It is involved in the conversion of the written word to its auditory equivalent. Lesion leads to alexia. Supramarginal and angular gyrus together comprise the inferior parietal lobule.
Supramarginal gyrus/Area 40 - \{Fig. 4) Surrounds the posterior end of the lateral sulcus. Lesions lead to conductive aphasia, facial apraxia and astereognosis.

Wernicke's area is the region of confluence of different sensory interpretation areas. Somatic, visual and auditory association areas meet here. It plays the greatest single role of any part of cerebral cortex in the higher levels of brain that we call intelligence. It comprehends spoken language and recognises familiar sounds and words.

The principle of functional lateralisation in the brain is universally accepted. Lateral specialisation makes possible a larger complement of talents that may be useful in survival, more the functions represented in the brain the greater will be the diversity of endowment within the species so that some members will survive almost any new threat.

Attempts have been made to find anatomical substrates to account for the functional asymmetries. In this study, the lateral sulcus, planum temporale, Heschl's gyrus of both hemispheres have been concentrated upon.

\section{Length of Lateral Sulcus}

In this study, it was found that the post-central horizontal segments of the left lateral sulcus was longer than the corresponding segment on the right in $90 \%$ of the specimens (Table 1). This pattern caused a reduction in the length of the right planum temporale. The observations of this study conforms with the works of Eberstaller (1890), Shellshear (1937) and Connelly (1950) who noted the left lateral sulcus to be longer than the right and with Rubens et al (1976) who pointed out that the post-central horizontal segments of the lateral sulcus were longer on the left in $86 \%$ of brains. 1

In $10 \%$ of specimens in the present series, the post-central horizontal segments were of equal length on the left and right (Table 1).

Early bending of the posterior ramus of the right lateral sulcus was noticed in $90 \%$ of the specimens. Studies conducted by Rubens et al (1976) showed similar findings. ${ }^{1}$ Such observations were also obtained in angiographic studies which showed a sharp upward inclination of the right lateral sulcus (Le May, 1972)2. Simon Keller and John Highley have documented asymmetry in sulci adjacent to speech area. ${ }^{3}$

The early bending of the posterior ramus of the right lateral sulcus leads to reduce the relative anteroposterior extent of the right parietal operculum. There was a relative expansion of the inferior parietal lobule on the right in such cases.

The inferior parietal lobule is formed by the supramarginal gyrus and the angular gyrus. As the areas for stereognosis and storage of visual images are represented in the inferior parietal region, a wider area for representation is significant. Lesions in this area may give rise to astereognosis, anomic aphasia and disorder of symbolic languages representation particularly alexia and agraphia. The reduction in size of the parietal operculum leads to the reduction in the sensory areas concerned with languages. Such persons may have difficulty in comprehension of languages. There is relative expansion in such cases of the inferior parietal lobule where the centres for stereognosis and visual auditory conversion are located. This may be a compensatory mechanism for those persons with reduced comprehension of language. Asymmetry in the cortical areas for language may be related to language disorders. Christiana Leonard and Mark have reported that 
individuals with large asymmetrical structures are more likely to have isolated phonological deficits. ${ }^{4}$

\section{Planum Temporale}

In the present study, $90 \%$ of specimens showed a larger left planum temporale (Table 1). In $8 \%$ of specimens, the left and right planum were of the same size. $2 \%$ of cases showed the right planum to be larger than the left planum. Geschwind and Levitsky (1968)5, Witelson and Pallie (1973)6, Wada, Clarke, Hamm (1975) ${ }^{7}$, Rubens et al $(1976)^{1}$, Chi et al (1977) ${ }^{8}$, Galaburda (1978) ${ }^{9}$, Falzi et al (1982) ${ }^{10}$ reported larger left planum temporale in majority of their cases. Magnetic resonance studies of the planum temporale (Steinmetz et al, 1991) revealed that the planum temporale asymmetry is correlated with hand dominance. They found that left handers had a significantly lesser degree of leftward planum temporale asymmetry than right handers. 11 Other magnetic resonance studies \{Foundas et al (1994), Schlaug et al (1995)\} too observed that the planum temporale showed a leftward asymmetry. ${ }^{12,13} \mathrm{~A}$ strong leftward asymmetry in the planum temporale in subjects with left hemisphere speech representations was demonstrated in the study conducted by Moffat et al. ${ }^{14}$ Results of volumetric MRI studies in righthanded subjects suggest a high occurrence of leftward asymmetry for white matter content in the language related areas (Pujol J Lopez - Sala et al). ${ }^{15}$

Herve PY et al have compared left and right-handed subjects in their study which revealed right-handed subjects to have more leftward planum temporale asymmetry. 16

The linear measurements of planum temporale in this study indicated a marked anatomical asymmetry. The left planum was found to be significantly larger than the right, thus confirming previous works. The findings of a left right anatomical asymmetry indicate that the planum temporale is one of the cortical surfaces for which there is a consistent left right asymmetry across individuals. This asymmetry occurs in a language relevant area. Hence, the findings may be of considerable implication. The length and early bending of the lateral sulcus determines the size of the planum temporale.

\section{Heschl's Gyrus}

Among the 50 brains ranging from $10-80$ years, 49 specimens showed single Heschl's gyrus on both sides (Table 1). Only one specimen had double Heschl's gyri and that was on the left. A comparatively bigger Heschl's gyrus was observed on the left side in three specimens. It was also noted that the specimen that had a larger right planum temporale showed a larger Heschl's gyrus on the right.

The findings of this study differ from Chi et al (1977) who have reported that the transverse temporal gyri are larger in number and extent on the right side in $54 \%$ of specimens and also with Penhune and Zatorre who have recorded the left Heschl's gyrus to be more extensive.8,17 Moreover, the presence of a larger gyrus in our study may also be significant. Our observations are not consistent with studies conducted by Marie D \& Jobard G who reported the occurrence of duplication of the gyrus more on the right side. ${ }^{18}$

\section{CONCLUSIONS}

Cerebral asymmetry of the human brain with regards to the lateral sulcus, planum temporale and Heschl's gyrus was confirmed.
As the study included only right handers, a left-sided dominance for language was observed. The absence of left handers in this series makes it difficult to give a definite statement relating handedness to asymmetry in the language areas. It may be possible to determine cerebral dominance by studying the pattern of lateral sulcus.

Language disorders are now being reported more and more as a result of the increasing literacy and awareness among the public. In children with a family history of language disorders, it may be worthwhile to train the right hemisphere to take up the functions of speech. To conclude it may be said that this is a field which requires a lot of research. The observations of this study suggest that there is an anatomical basis for language dominance to the left side, substantiated by gross studies. These observations may be applied in the future therapeutic strategies of adult as well as child language disorders. Future developments in research in this area can throw light on the mechanisms of normal language acquisition and resolution. These principles may be applied in the total rehabilitation of various types of language disorders.

\section{REFERENCES}

1. Rubens AB, Mahowald MW, Hutton JT. Asymmetry of the lateral (Sylvian) fissures in man. Neurology 1976;26 (7):620-4.

2. LeMay M, Culebras A. Human brain-morphological differences in the hemisphere demonstrable by carotid angiography. N Engl J Med 1972;287(4):168-70.

3. Keller SS, Highley JR, Garcia-Finana M, et al. Sulcal variability, stereological measurement and asymmetry of Broca's area on MR images. Journ of Anatomy 2007;211(4):534-55.

4. Leonard CM, Eckert MA. Asymmetry and Dyslexia. Dev Neuropsychol 2008;33(6):663-81.

5. Geschwind $\mathrm{N}$, Levitsky $\mathrm{W}$. Human brain: left-right asymmetries in temporal speech region. Science 1968;161(3837):186-7.

6. Witelson SF, Pallie W. Left hemisphere specialization for language in the newborn. Brain 1973;96(3):641-6.

7. Wada JA, Clarke R, Hamm A. Cerebral hemispheric asymmetry in humans. Cortical speech zones in 100 adults and 100 infant brains. Arch Neurol 1975;32(4):239-46.

8. Chi JG, Dooling EC, Gilles FH. Left right asymmetries of temporal speech areas of the human foetus. Arch Neurol 1977;34(6):346-8.

9. Galaburda AM, Sanides F, Geschwind N. Human braincytoarchitectonic left right asymmetries in the temporal speech region. Arch Neurol 1978;35(12):812-7.

10. Falzi G, Perrone P, Vignolo LA. Right left asymmetry in anterior speech region. Arch neurol 1982;39(4):239-40.

11. Steinmetz H, Volkmann J, Jancke L, et al. Anatomical leftright asymmetry of language related temporal cortex is different in left and right handers. Ann Neurol 1991;29(3):315-9.

12. Foundas AL, Leonard CM, Gilmore R, et al. Planum temporale asymmetry and language dominance. Neuropsychologia 1994;32(10):1225-31.

13. Schlaug G, Jäncke L, Huang Y, et al. In vivo evidence of structural brain asymmetry in musicians. Science 1995;267(5198):699-701. 
14. Moffat SD, Hampson E, Lee DH. Morphology of the planum temporale and corpus callosum in left handers with evidence of left and right hemisphere speech representation. Brain 1998;121(Pt 12):2369-79.

15. Pujol J, Lopez-Sala A, Deus J, et al. The lateral asymmetry of the human brain studied by volumetric magnetic resonance imaging. Neuroimage 2002;17(2):670-9.

16. Herve PY, Crivello F, Perchey G, et al. Handedness and cerebral anatomical asymmetries in young adult males. Neuroimage 2006;29(4):1066-79.
17. Penhune VB, Zatorre RJ, MacDonald JD, et al. Interhemispheric anatomical differences in human primary auditory cortex: probabilistic mapping and volume measurement from magnetic resonance scans. Cerebral Cortex 1996;6(5):661-72.

18. Marie D, Jobard G, Crivelli F, et al. Descriptive anatomy of Heschl's gyri in 430 healthy volunteers, including 198 lefthanders. Brain Str Funct 2015;220(2):729-43. 